\title{
A CONTRIBUIÇÃO DE MULHERES LÍDERES NO NÍVEL DE COMPROMETIMENTO ORGANIZACIONAL
}

THE CONTRIBUTION OF WOMEN LEADERS IN THE LEVEL OF ORGANIZATIONAL COMMITMENT

\author{
ALEX SANDRO QUADROS WEYMER ${ }^{1}$ \\ KATRINE JULIANE SCHUBER ${ }^{2}$ \\ ANDREA SARRIA ESKENAZI ${ }^{3}$ \\ PAOLA APARECIDA DE LIMA MARTINS ${ }^{4}$
}

\begin{abstract}
RESUMO: O objetivo desta pesquisa foi verificar a contribuição de mulheres líderes no nível de comprometimento organizacional, bem como identificar qual é o estilo predominante na liderança feminina a partir da percepção dos liderados. A escolha teórica sobre liderança é respaldada no trabalho de Bass (1985) e Bass e Avolio (2004), com ênfase nos estilos de liderança transformacional e liderança transacional, e nos trabalhos de Meyer e Allen (1991, 1997), que organizaram as várias significações de comprometimento em três categorias: afetivo, normativo e calculativo. A estratégia de pesquisa é do tipo survey, de caráter predominantemente quantitativo, e os dados foram tratados utilizando a estatística descritiva e correlação paramétrica, após verificada a normalidade dos dados. Os resultados evidenciaram que a liderança transformacional é significativamente relacionada com as dimensões afetiva e normativa do comprometimento organizacional. Como a relação é positiva, foi possível identificar que os liderados que percebem em sua líder um perfil transformacional, apresentam um maior grau de comprometimento nestas duas dimensões. Foi possível identificar também, que o estilo de liderança mais presente na liderança feminina é o transformacional, com maior média no constructo motivação inspiradora, e que existe uma correlação moderada entre a liderança transformacional e o comprometimento afetivo e normativo.
\end{abstract}

Palavras-chave: Liderança feminina. Comprometimento organizacional. Liderança transformacional. Liderança transacional.

ABSTRACT: The purpose of this article was to verify the influence of a female leadership on the organizational commitment and identify the predominant in the female leadership style. The theoretical choice of leadership is supported by the work of Bass (1985) and Bass and Avolio (2004), with emphasis on transformational and transactional leadership styles developed by Meyer e Allen $(1991,1997)$ based on three categories: affective, normative and calculative. The method is a predominantly quantitative survey, and the data were treated using descriptive statistics and parametric correlation. The results showed that transformational leadership is significantly related to the affective and normative dimensions of organizational commitment. It is possible to identify that the leaders who perceive in their leader a transformational profile, present a greater degree of commitment

Data de submissão: 15/10/2017. Data de aceite: 25/11/2017. Data de publicação: 17/12/2018.

\footnotetext{
1 Programa de Pós-Graduação em Gestão de Cooperativas-PGCOOP. Escola de Negócios/Pontifícia Universidade Católica do Paraná. Endereço: Rua Imaculada Conceição, 1155 - Bairro Prado Velho, Curitiba - PR. CEP: 80.215-901. Email: alex.weymer@pucpr.br

2 Escola de Negócios/Pontifícia Universidade Católica do Paraná.

${ }^{3}$ Escola de Negócios/Pontifícia Universidade Católica do Paraná.

${ }^{4}$ Escola de Negócios/Pontifícia Universidade Católica do Paraná.
} 
in these two dimensions. It was also possible to identify that the leadership style most present in female leadership is transformational, with a higher average in the inspirational motivational construct, and that there is a moderate correlation between transformational leadership and affective and normative commitment.

Keywords: Female leadership. Organizational commitment. Transformational leadership. transactional leadership.

\section{INTRODUÇÃO}

A compreensão do papel das mulheres líderes no contexto organizacional parece assumir relevância cada vez mais significativa, tanto da perspectiva gerencial quanto acadêmica, especialmente em ambientes altamente competitivos, no qual os resultados de equipes parecem depender cada vez mais da congruência entre expectativas organizacionais e individuais. Tal interesse justifica-se não somente pela tendência de empoderamento da liderança e sua influência sobre o comportamento dos funcionários (LEE; WILLIS; TIAN, 2017), mas especialmente da concepção estereotipada, de que os comportamentos de trabalho inovadores são atribuídos mais aos homens do que às mulheres (LUKSYTE; UNSWORTH; AVERY, 2017).

Trabalhos recentes, como o de Post (2015), evidenciam a importância de compreender em que medida e em que contextos as mulheres líderes podem ser vantajosas para equipes de trabalho, por meio da criação de um ambiente favorável para estimular equipe coesas, aprendizado cooperativo e comunicação participativa. O grande desafio, porém, reside na capacidade de equilibrar interesses organizacionais - tradicionalmente focados em resultados amparados por uma lógica instrumental - com interesses individuais, de modo que as motivações individuais não sejam sustentadas somente por mecanismos de troca com perspectivas duradouras limitadas.

É nesse sentido que a inclusão do comprometimento organizacional justifica-se como a principal variável dependente do presente estudo, uma vez que os motivos que levam determinados funcionários a estarem comprometidos, parecem variar diante da diversidade e interesses peculiares, inerentes à individualidade, caracterizado por "múltiplos focos (valores, organização, carreira, trabalho e sindicato) e múltiplas bases de dimensões afetiva, normativa, de continuidade, comportamental e sociológica" (SANTOS FILHO; MOURÃO, 2011).

Diante do exposto, o objetivo principal desta pesquisa é verificar a contribuição de líderes mulheres no nível de comprometimento organizacional. A escolha teórica sobre liderança é respaldada no trabalho de Bass (1985) e Bass e Avolio (2004), com ênfase nos estilos de liderança transformacional, composta pela análise dos componentes: influência idealizada (atribuída), influência idealizada (comportamento), motivação inspiradora, estímulo intelectual e consideração individual; e liderança transacional, composta pelos componentes: recompensa contingente e gerenciamento por exceção. Quanto à variável comprometimento organizacional, o recorte tem como suporte teórico o trabalho de Meyer e Allen $(1991,1997)$, que organizaram as várias significações de comprometimento em três categorias: afetivo, calculativo e normativo. O instrumento de mensuração de ambas variáveis tem, portanto, respaldo científico a partir de escalas validadas e que foram testadas nos estudos supracitados.

Para atender ao objetivo da pesquisa, este artigo está dividido em cinco seções. A primeira refere-se à introdução que apresentou o contexto e as justificativas teóricas e práticas para a realização da pesquisa. A segunda aborda os estudos realizados sobre 
liderança com ênfase da atuação da mulher como líder e comprometimento organizacional. Em seguida, são apresentados os procedimentos metodológicos que respaldam a apresentação dos resultados. A quarta parte apresenta a análise dos resultados obtidos e, para finalizar, destacam-se as conclusões, limitações e recomendações para pesquisas futuras.

\section{FUNDAMENTAÇÃO TEÓRICO-EMPÍRICA}

A fundamentação teórica apresenta uma compreensão acerca do conceito de liderança, com ênfase nos de estilos de liderança transformacional e transacional, liderança feminina e comprometimento organizacional.

\subsection{Liderança transacional e transformacional}

Embora o tema liderança seja amplamente estudado e mencionado no cotidiano e no contexto organizacional, não existe um consenso entre suas teorias e abordagens. No entanto, há concordância quanto à liderança estar diretamente relacionada ao conceito de influência, uma vez que define uma direção, orientando os esforços de determinado grupo ao alcance das metas do líder (GRIFFIN; MOORHEAD, 2015).

Os estudos sistemáticos sobre liderança surgiram no início do século $\mathrm{XX}$, com a teoria dos traços, caracterizada pela abordagem da personalidade do líder, passando pelas teorias comportamentais, situacionais e contingenciais. Contemporaneamente, a partir de 1980, ganham forças as teorias da liderança carismática, liderança transformacional e transacional, bem como o conceito laissez-faire, caracterizado como a abdicação do líder na tomada das decisões. Diante das diversas possibilidades sobre o tema, optou-se como arcabouço teórico para esta pesquisa, os estilos de liderança transformacional e transacional, com o objetivo de analisar com maior profundidade a partir de um recorte que tem sido amplamente estudado, tanto internacionalmente (BASS, 1985; 1989; 1998; BASS; AVOLIO, 2004; BASS; BASS, 2008; BLACKWELL, 2003; BOEHM et al., 2014; RIJAL, 2010) , quanto nacionalmente (GODOY et al., 2017; WEYMER; MOREIRA, 2017; CORTÊS, 2016; CARNEIRO; ABELHA; CAVAZOTTE, 2015).

O conceito de liderança transformacional surgiu em 1978, introduzido pelo especialista em liderança James MacGregor Burns. Para ele, esse estilo de liderança se dá quando líderes e liderados interagem em um nível alto de moral e comprometimento. Este estilo de liderança proporciona um ambiente favorável para o desenvolvimento das pessoas, reconhece e satisfaz necessidades, além de desenvolver culturas organizacionais que proporcionem o crescimento individual. (ARAúJO, 2011).

Apesar de introduzido por Burns, o conceito de liderança transformacional apresentado por Bass (1985), é considerado uma das mais notórias contribuições para o tema, já que diferenciou e ampliou as noções dos estilos transformacional e transacional de liderar. (AGOSTINHO, 2014). Para Bass (1985), na liderança transformacional os líderes inspiram seus liderados a superarem os padrões de desempenho, por meio de expectativas que os desafiam a entregar além do planejado. Nesse sentido, a "liderança transformacional refere-se ao conjunto de habilidades que permite que um líder reconheça a necessidade de uma mudança e execute esta mudança de forma bem-sucedida" (GRIFFIN; MOORHEAD, 2015, p. 348).

Ao contrário da liderança transacional, que visa barganha de valores, a liderança transformacional envolve relação entre líderes e liderados num nível superior de motivação e moralidade, justamente como resultado dessa interação social. Na liderança transacional, o liderado é recompensado sempre que atinge a uma demanda, caso contrário, o líder 
transacional não estimula o sentimento de autorrealização em sua equipe (BASS; BASS; 2008).

Para avaliar a manifestação da liderança transacional e transformacional, Bass e Avolio (2004) desenvolveram o Multifactor Leadership Questionnaire (MLQ), um questionário que mensura o tipo de liderança presente a partir de questões respondidas pelo ponto de vista dos subordinados ao avaliarem seus líderes.

\subsection{Liderança Feminina}

Griffin e Moorhead (2015) destacam que um fator que está alterando os estudos sobre liderança, é a presença crescente da mulher em altos níveis de gestão, num contexto no qual a grande maioria das teorias e pesquisas sobre o tema, tem foco no líder do gênero masculino. Essa premissa é sustentada por Helgesen (2000, p. 60) ao afirmar que "mulheres começaram a assumir posições de autoridade real e a influenciar áreas que antes eram exclusivas dos homens".

Tal assertiva pode ser corroborada pelo trabalho de Post (2015), que ao buscar compreender em que medida as mulheres líderes podem ser vantajosas para os times de trabalho, concluiu que a liderança feminina se associa mais positivamente à coesão em equipes maiores e diversificadas, associada à aprendizagem cooperativa e à comunicação participativa em equipes maiores e geograficamente dispersas. Embora o estudo tenha limitações de generalizações, é possível notar que as mulheres líderes naquele contexto específico de referência, possuem competências capazes de articular aspectos comportamentais com objetivos organizacionais em ambientes mutáveis e complexos.

É mister reconhecer que existem evidências sobre a amplitude e importância significativa da mulher nos contextos organizacionais, todavia, ainda é possível perceber que muitos trabalhos inovadores são atribuídos mais aos homens do que às mulheres. Devido a este viés, foi identificado no estudo de Luksyte, Unsworth e Avery (2017), que as mulheres que inovam não recebem melhores avaliações de desempenho do que as que não inovam, ao passo que o engajamento em trabalhos inovadores, é benéfico para os homens.

Embora existam tentativas de distinção entre homens e mulheres no papel de líderes, parece pouco provável a identificação de características de gênero e desempenho com cunho generalista. No entanto, existem alguns padrões podem ser percebidos à medida que pesquisas sobre o tema avançam, e que podem servir de premissas que direcionam em direção à formulação de hipóteses.

Pesquisas iniciais apontam diferenças fundamentais na liderança de homens e mulheres e em contraste aos estereótipos conhecidos, indicam que líderes mulheres não são necessariamente mais educativas e incentivadoras do que os homens, e líderes homens não são mais ásperos, controladores ou focados na tarefa do que líderes mulheres. A diferença que parece surgir em alguns casos, é que mulheres tendem a ser mais democráticas ao tomar decisões, enquanto homens tendem a ser mais autocráticos. (GRIFFIN; MOORHEAD, 2015).

\subsection{Comprometimento Organizacional}

O interesse para identificar o nível de comprometimento e suas respectivas dimensões, tem sido foco de interesse de estudos organizacionais. Tal compreensão, também permite subsidiar gestores para tomada de decisões em diferentes ambientes de trabalho, uma vez que a reciprocidade pode ser a principal base para alinhamento de expectativas, como pode ser observado no trabalho de Ferreira (2011), que direciona para o fato de que os 
funcionários se tornam comprometidos quando sentem que a empresa também está comprometida com eles.

O tema comprometimento apresenta muitas opções e transversalidades para ser analisado sob diferentes perspectivas, incluindo recortes longitudinais com o objetivo de verificar a sustentabilidade do comprometimento a longo prazo (GAO-URHAHN;, BIEMANN; JAROS, 2016), o papel da organização como influência positiva do apoio percebido no desempenho do funcionário e compromisso afetivo (NAZIR; ISLAM 2017), bem como da relação da liderança com comprometimento (PIZZI, 2017; YAHAYA; EBRAHIM, 2016; MACIEL; REINART, 2009).

Para o interesse específico desta pesquisa, optou-se pelo modelo multidimensional proposto por Meyer e Allen $(1991,1997)$, que separa o comprometimento em três dimensões: afetivo, normativo e calculativo (ou instrumental).

De acordo com esses autores, na dimensão afetiva, o indivíduo está emocionalmente ligado à organização e sente que quer permanecer nela, evidenciando que o desejo é o estado psicológico manifesto. Na dimensão normativa, o indivíduo possui um dever moral com a organização, evidenciado um sentimento de obrigatoriedade de permanência. Já na dimensão calculativa, o indivíduo só permanece na organização porque acredita ter a necessidade com base numa relação instrumental, ou seja, permanece pela ausência de alternativas de emprego ou pelos sacrifícios que terá ao sair. Nessa última, a necessidade é o estado psicológico desta dimensão.

Em outras palavras, o comprometimento normativo retrata o sentimento de obrigação de ficar na empresa em decorrência de motivos éticos ou morais. O calculativo se explica por meio da percepção de importância em permanecer na empresa devido à remuneração recebida. Percebe-se, no entanto, que talvez o comprometimento afetivo seja aquele que proporciona um sentimento de pertença, no qual a permanência ocorre por consentimento, e não por mecanismos condicionantes. No entanto, independentemente do tipo de comportamento organizacional presente, o líder parece ter um papel fundamental para garantir que sua equipe esteja engajada e comprometida com os objetivos e metas da empresa.

\section{PROCEDIMENTOS METODOLÓGICOS}

O delineamento da presente investigação contemplou decisões quanto a método, amplitude temporal, unidade e nível de análise e delimitação, conforme os elementos destacados por Babbie (2007). A estratégia de pesquisa é do tipo survey, de caráter predominantemente quantitativo, indicado para estudos descritivos, que procuram estabelecer uma causalidade entre fenômenos. De acordo com Hair et al. (2009) este procedimento coleta os dados primários a partir da resposta de indivíduos de um determinado grupo.

A pesquisa adota corte transversal em sua dimensão temporal. O nível de análise é individual e a unidade de análise é o indivíduo (BABBIE, 2007). A população foi constituída por profissionais liderados por gestoras mulheres da cidade de Curitiba (PR) identificados por redes sociais, mas que não tinham qualquer relação entre si, caracterizando uma amostra não probabilista, por conveniência. Segundo Neto (2002), esta situação pode ocorrer com muita frequência na prática, devido à impossibilidade da realização de censo e da inacessibilidade a toda uma população.

O instrumento de coleta de dados integrou dois questionários validados contemplando as duas principais variáveis da presente pesquisa: liderança (transacional e 
transformacional) e comprometimento organizacional (afetivo, normativo e calculativo), ambos com assertivas dispostas na seguinte escala de cinco níveis: discordo fortemente, discordo, não concordo nem discordo, concordo, concordo fortemente.

Em relação à escala para mensuração da liderança, a versão original possui 45 questões, divididas em 12 componentes, no entanto, para este estudo utilizou-se 28 questões, divididas em 07 componentes, avaliando apenas os estilos transformacional e transacional, que é o foco desta pesquisa. Os dados relativos ao comprometimento foram coletados por meio da última versão do questionário proposto por Meyer e Allen (1991, 1997), dividido em três categorias (afetiva, normativa, calculativa), atendidos por 19 itens, sendo 04 com escalas invertidas, mas que foram devidamente colocadas na ordem no momento da tabulação dos dados. Além das escalas supracitadas, ao final do instrumento foram coletadas as informações sociodemográficas. Os questionários respondidos foram todos válidos, totalizando uma amostra final de 106 observações.

Para análise estatística recorreu-se ao software Statistical Package for Social Sciences ${ }^{\circledR}$ (SPSS), versão 20 para Windows. Na análise e interpretação dos dados utilizou-se a estatística descritiva que permitiu verificar a normalidade dos dados, evidenciando que todos valores de assimetria e curtose estão no intervalo de 3 e -3. Mais especificamente, 0 maior valor de assimetria foi de $-1,458$, e o maior valor de curtose foi de 2,659 . Como os dados os dados apresentaram uma distribuição próxima da normalidade (MARÔCO, 2003), optou-se pela correlação paramétrica para identificar a relação entre as variáveis independentes (liderança transformacional e transacional) e dependentes (comprometimento afetivo, normativo e calculativo).

Para Neto (2002), este tipo de estatística se preocupa com a organização e descrição de dados e pode ser empregada em qualquer ramo do conhecimento onde dados experimentais são manipulados.

A confiabilidade interna das escalas foi testada utilizando o Alfa de Cronbach, que avalia o grau de consistência entre múltiplas medidas de uma variável, garantindo que os itens da escala meçam adequadamente o mesmo constructo e sejam altamente correlacionados. O limite inferior aceito varia entre 0,60 e 0,70. (HAIR, 2009).

Também realizada a análise de regressão que, segundo Hair et al. (2009), além de avaliar objetivamente o caráter da relação, determina a importância relativa de cada variável independente e a medida dependente.

O grau de relacionamento entre os estilos de liderança e as categorias do comprometimento organizacional foi obtido calculando o coeficiente de correlação linear de Person. Este coeficiente possui as importantes propriedades de ser adimensional e variar entre -1 e +1 , quanto mais próximo estiver de 1 ou -1 , mais forte é a associação linear entre as duas variáveis. (NETO, 2002).

Com o objetivo de verificar se houve diferença significativa entre a variável gênero e os estilos de liderança identificados utilizou-se o Teste $t$ de Student. Para Hair et al. (2009) o teste $t$ mostra se a diferença das médias decorre da variabilidade amostral ou se apresentam uma diferença verdadeira.

\section{APRESENTAÇÃO E ANÁLISE DE DADOS}

$\mathrm{Na}$ sequência são apresentados os resultados da pesquisa, notadamente, os dados pertinentes à amostra, a análise da confiabilidade das escalas, a descrição das médias e intervalo de confiança, as relações e correlações entre as variáveis, além, de teste 
complementar, relativo à percepção de homens e mulheres, quanto ao estilo feminino de liderar.

\subsection{Perfil dos respondentes}

Em função da impossibilidade de um censo, empregou-se a amostragem não probabilística por conveniência, resultando em uma amostra final de 106 questionários respondidos. Destaca-se que $78,3 \%$ dos indivíduos foram mulheres, $44,3 \%$ de todos os respondentes encontram-se na faixa etária de 20 a 29 anos, 58,5\% trabalham em empresas de grande porte e o setor que possui maior número de respondentes é o setor de prestação de serviços, com $43,4 \%$, seguido pelo setor industrial, com $35,8 \%$ de indivíduos.

\subsection{Análise da consistência interna das escalas}

A seguir apresenta-se a análise da consistência interna da escala liderança transformacional e transacional obtidos na análise dos resultados da pesquisa.

Tabela 1 - Consistência Interna Escala Liderança Transformacional e Liderança Transacional

\begin{tabular}{clcc}
\hline Tipos de Liderança & Escalas & Alfa de Cronbach & N de Itens \\
\hline Liderança Transformacional & 0,935 & 20 \\
& Influência Idealizada (Atribuída) & 0,828 & 4 \\
& Influência Idealizada (Comportamento) & 0,649 & 4 \\
& Motivação por Inspiração & 0,850 & 4 \\
& Estímulo Intelectual & 0,805 & 4 \\
Liderança Transacional & Consideração Individual & 0,821 & 4 \\
& & 0,747 & 8 \\
& Recompensa de Contingente & 0,659 & 4 \\
& Gerenciamento por Exceção (Ativo) & 0,645 & 4 \\
\hline
\end{tabular}

Fonte: dados primários

O Alfa de Cronbach para liderança transformacional é superior a 0,90, indicando segundo Malhotra (2011), uma confiabilidade muito alta $(0,935)$. Significa que as 20 variáveis medem de forma adequada a dimensão liderança transformacional.

Os constructos Influência Idealizada (Atribuída), Motivação Inspiradora, Estímulo Intelectual e Consideração Individual, possuem o valor da alfa, maior que 0,80 , indicando alta confiabilidade, e que suas variáveis são medidas de forma adequada. 0 constructo Influência Idealizada (Comportamento) obteve o valor de alfa de 0,649, indicando que suas quatro variáveis medem de forma aceitável a Influência Idealizada (Comportamentos).

Para a liderança transacional, o alfa foi superior a 0,70, indicando uma confiabilidade alta, suas 08 variáveis medem adequadamente a dimensão Liderança Transacional. Os constructos Recompensa de Contingente e Gestão por Exceção - Ativo, possuem alfa superior a 0,60, valor que segundo Hair et al (2009), é aceitável.

Análise da consistência interna da escala Comprometimento Organizacional: 
Tabela 2 - Consistência Interna Escala Comprometimento Organizacional

\begin{tabular}{rcc}
\hline & Alfa de Cronbach & N de Itens \\
\hline Comprometimento Organizacional & 0,864 & 19 \\
Afetivo & 0,850 & 6 \\
Normativo & 0,799 & 6 \\
Calculativo & 0,930 & 7 \\
\hline
\end{tabular}

Fonte: dados primários

O alfa de cronbach para o comprometimento organizacional foi superior a 0,80 , indicando alta confiabilidade e que suas 19 variáveis medem adequadamente a dimensão Comprometimento Organizacional.

Todas as categorias possuem alfa maior que 0,70 , ou seja, todas as suas variáveis são medidas de forma adequada. A escala demostra-se adequada para medir as categorias do comprometimento organizacional.

\subsection{Análise descritiva e intervalo de confiança para as escalas}

Apresentam-se os intervalos de confiança para as escalas dos questionários e todas as suas dimensões. Esta análise permite realizar a inferência comparativa dos resultados obtidos para cada uma das dimensões em estudo.

Tabela 3 - Análise Descritiva das Médias e Intervalo de Confiança para a Escala Liderança Transformacional e Liderança Transacional

\begin{tabular}{lllll}
\hline \multicolumn{1}{c}{ MLQ } & N & Média & Desvio Padrão & Coef. Variação \\
Liderança Transformacional & 106 & 3,67 & 0,68 & $19 \%$ \\
Influência Idealizada (Atributos) & 106 & 3,55 & 0,89 & $25 \%$ \\
Influência Idealizada (Comportamentos) & 106 & 3,66 & 0,70 & $19 \%$ \\
Motivação Inspiradora & 106 & 3,85 & 0,78 & $20 \%$ \\
Estimulação Intelectual & 106 & 3,75 & 0,75 & $20 \%$ \\
Consideração Individual & 106 & 3,52 & 0,90 & $26 \%$ \\
Liderança Transacional & 106 & 3,34 & 0,62 & $18 \%$ \\
Recompensa de contingente & 106 & 3,40 & 0,70 & $21 \%$ \\
Gestão por exceção (ativa) & 106 & 3,29 & 0,74 & $22 \%$ \\
\hline
\end{tabular}

Fonte: dados primários

A análise descritiva das médias revela que a liderança transformacional possui média superior à liderança transacional, e ambas apresentam médias superiores ao valor intermédio da escala. Os constructos da liderança transformacional que apresentam as maiores médias são Motivação Inspiradora e Estimulação Intelectual, seguidos pela Influência Idealizada (Comportamentos) e Influência Idealizada (Atributos). A menor média é da Consideração Individual.

Para os constructos da liderança transacional, a maior média foi Recompensa de Contingente, seguida por Gestão por Exceção (Ativa), esta diferença também não é estatisticamente significativa.

Pode-se inferir que os liderados identificam mais a presença do estilo transformacional em suas líderes, principalmente pela motivação Inspiradora e estimulação intelectual. 
Tabela 4 - Análise Descritiva das Médias e Intervalo de Confiança para a Escala Comprometimento Organizacional

\begin{tabular}{lllll}
\hline Comprometimento Organizacional & $\mathrm{N}$ & Média & Desvio Padrão & Coeficiente de Variação \\
Afetivo & 106 & 3,65 & 0,79 & 21,67 \\
Normativo & 106 & 3,36 & 0,76 & 22,48 \\
Calculativo & 106 & 3,25 & 0,66 & 20,33 \\
\hline
\end{tabular}

Fonte: dados primários

Para esta amostra, a categoria do comprometimento organizacional que obteve a maior média foi a Afetiva, seguida da Normativa, não existindo diferenças estatisticamente significativas entre as duas. Infere-se que existe um elevado grau de comprometimento dos liderados nas três categorias, pois os limites dos intervalos inferiores de confiança são superiores ao ponto intermédio da escala de medida. O comprometimento é maior nas dimensões afetiva e normativa.

\subsection{Relação entre os estilos de liderança e o comprometimento organizacional}

A equação de regressão para as variáveis independentes liderança transformacional e liderança transacional e a variável dependente da dimensão afetiva do comprometimento resultou no coeficiente de determinação $R^{2}=0,196$, indicando que $19,60 \%$ da variação que ocorre na variável dependente dimensão afetiva do comprometimento é explicada pelas variáveis incluídas no modelo.

O teste $F$, à significância global do modelo é validado, pois apresentou $p<0,001$, o que permite rejeitar a hipótese de não existirem variáveis independentes significativas para o modelo.

Tabela 5 - Coeficientes das variáveis no modelo e nível de significância

\begin{tabular}{lllll}
\hline & $\mathrm{bi}$ & $\mathrm{s}(\mathrm{bi})$ & $\mathrm{t}$ & $\mathrm{p}$ \\
\hline (Constante) & 1,571 & 0,422 & 3,721 & 0,000 \\
Liderança Transformacional & 0,330 & 0,131 & 2,590 & 0,011 \\
Liderança Transacional & 0,249 & 0,145 & 1,714 & 0,090 \\
\hline
\end{tabular}

Notas: bi e s(bi) - estimativas do coeficiente e do seu desvio padrão para a variável i.

$\mathrm{t}$ - Estatística do teste $\mathrm{t}$ de Student.

Fonte: dados primários

As variáveis do modelo indicam que a liderança transformacional $(p=0,011)$ é significativa para explicar a dimensão afetiva do comprometimento. O coeficiente é positivo, ou seja, a dimensão afetiva do comprometimento aumenta para quem identifica mais em sua líder, o estilo transformacional de liderança. A liderança transacional $(p=0,090)$ não apresenta uma relação estatisticamente significativa com a variável dependente.

$\mathrm{Na}$ relação entre as variáveis independentes liderança transformacional e liderança transacional com a variável dependente comprometimento normativo, o coeficiente de determinação $\left(R^{2}=0,132\right)$ indica que $13,20 \%$ da variação que ocorre na variável dependente dimensão normativa do comprometimento, é explicada pelas variáveis incluídas no modelo. O coeficiente de determinação ajustado é de $11,5 \%$.

$O$ teste $F$ valida a significância global do modelo, pois apresentou $p=0,030$, o que permite rejeitar a hipótese de não existirem variáveis independentes significativas para o modelo. 
Tabela 6 - Coeficientes das variáveis no modelo e nível de significância

\begin{tabular}{lllll}
\hline & $\mathrm{bi}$ & $\mathrm{s}(\mathrm{bi})$ & $\mathrm{t}$ & $\mathrm{p}$ \\
\hline (Constante) & 1,746 & 0,420 & 4,160 & 0,000 \\
Liderança Transformacional & 0,287 & 0,130 & 2,206 & 0,030 \\
Liderança Transacional & 0,168 & 0,144 & 0,167 & 0,246 \\
\hline
\end{tabular}

Notas: bi e s(bi) - estimativas do coeficiente e do seu desvio padrão para a variável i.

$\mathrm{t}$ - Estatística do teste $\mathrm{t}$ de Student.

Fonte: dados primários

As variáveis do modelo indicam que a liderança transformacional $(p=0,030)$ é significativa para explicar a dimensão normativa do comprometimento. Percebe-se que o coeficiente é positivo, ou seja, a dimensão afetiva do comprometimento aumenta para quem identifica mais em sua líder o estilo transformacional de liderar.

A liderança transacional $(p=0,246)$ não apresenta uma relação estatisticamente significativa com a variável dependente. O coeficiente de determinação $\left(R^{2}=0,024\right)$ das variáveis independentes liderança transformacional e liderança transacional com a variável dependente calculativa, indica que $2,4 \%$ da variação que ocorre na variável dependente na dimensão calculativa do comprometimento, é explicada pelas variáveis incluídas no modelo, sendo que o coeficiente de determinação ajustado é $0,5 \%$.

$\mathrm{O}$ teste $\mathrm{F}$ não valida a significância global do modelo, por apresentar valor de prova superior a $5 \%(p=0,287)$, o que não permite rejeitar a hipótese de não existirem variáveis independentes significantes para o modelo.

Tabela 7 - Coeficientes das variáveis no modelo e nível de significância

\begin{tabular}{lllll}
\hline & $\mathrm{bi}$ & $\mathrm{s}(\mathrm{bi})$ & $\mathrm{t}$ & $\mathrm{P}$ \\
\hline (Constante) & 2,798 & 0,389 & 7,195 & 0,000 \\
Liderança Transformacional & $-0,057$ & 0,121 & $-0,473$ & 0,637 \\
Liderança Transacional & 0,197 & 0,134 & 1,477 & 0,143 \\
\hline
\end{tabular}

Notas: bi e s(bi) - estimativas do coeficiente e do seu desvio padrão para a variável i.

$\mathrm{t}$ - Estatística do teste $\mathrm{t}$ de Student.

Fonte: dados primários

As variáveis do modelo indicam que a liderança transformacional $(p=0,637)$ e a liderança transacional $(p=0,143)$, não apresentam uma relação estatisticamente significativa com a variável dependente dimensão calculativa do comprometimento. Portanto, não é possível afirmar que as variáveis em estudo tenham um efeito significativo sobre a dimensão calculativa do comprometimento, ou seja, não se verifica uma relação entre os estilos de liderança e a dimensão calculativa do grau de comprometimento.

\subsection{Correlações entre os estilos de Liderança e as categorias do comprometimento organizacional}

Para dimensionar a intensidade da associação linear existente entre as variáveis em estudo, utilizou-se coeficiente de correlação linear de Pearson. Os resultados do teste são apresentados na Tabela 8. 
Tabela 8 - Coeficiente de Correlação de Pearson

\begin{tabular}{lllll} 
& & \multicolumn{2}{l}{ Comprometimento } & Calculativo \\
\cline { 3 - 4 } Liderança & Coeficiente Correlação & $0,416^{* *}$ & $0,347^{* *}$ & 0,057 \\
Transformacional & Valor de Prova & 0,000 & 0,000 & 0,563 \\
& $\mathrm{~N}$ & 106 & 106 & 106 \\
\hline \multirow{3}{*}{ Liderança Transacional } & Coeficiente Correlação & $0,379^{* *}$ & $0,301^{* *}$ & 0,148 \\
& Valor de Prova & 0,000 & 0,002 & 0,131 \\
& $\mathrm{~N}$ & 106 & 106 & 106 \\
\hline
\end{tabular}

Fonte: dados primários

Verifica-se correlação moderada entre a liderança transformacional e a categoria afetiva e correlação baixa com a categoria normativa do comprometimento organizacional. Ou seja, quem identifica em sua líder, o estilo de liderança transformacional, apresenta maior comprometimento afetivo e normativo. Para essa amostra, também ocorre correlação significativa entre a liderança transacional e as categorias afetiva e normativa, no entanto, ambas são baixas.

Quanto ao objetivo geral desta pesquisa, pode-se concluir que quem identifica em sua líder os estilos de liderança transformacional e transacional, apresenta maior comprometimento afetivo e normativo. Os dados revelam ainda que não há relação entre os estilos de liderança e o comprometimento calculativo.

\subsection{Diferenças entre a variável gênero (percepção dos liderados) e os estilos de liderança}

Procurando identificar em que medida homens e mulheres apresentam percepções diferenciadas quanto ao estilo de liderança identificado foi realizado o test t de Student para comparar se as médias dos dois gêneros diferem significativamente um do outro.

Tabela 9 - Teste $t$ de Student

\begin{tabular}{|c|c|c|c|c|c|c|c|}
\hline Fator & Gênero & $\mathbf{N}$ & Média & $\begin{array}{l}\text { Desvio } \\
\text { Padrão }\end{array}$ & $\mathbf{t}$ & $\begin{array}{l}\text { Graus de } \\
\text { Liberdade }\end{array}$ & $\mathbf{p}$ \\
\hline \multirow{2}{*}{$\begin{array}{l}\text { Liderança } \\
\text { Transformacional }\end{array}$} & Feminino & 83 & 3,64 & 0,72 & \multirow{2}{*}{$-0,628$} & \multirow{2}{*}{104} & \multirow{2}{*}{0,531} \\
\hline & Masculino & 23 & 3,75 & 0,54 & & & \\
\hline \multirow{2}{*}{ Liderança Transacional } & Feminino & 83 & 3,30 & 0,65 & \multirow{2}{*}{$-1,419$} & \multirow{2}{*}{104} & \multirow{2}{*}{0,159} \\
\hline & Masculino & 23 & 3,51 & 0,49 & & & \\
\hline
\end{tabular}

Fonte: dados primários

Para a Liderança transformacional o teste $t(t(104)=-0,628 ; p>0,05)$ mostrou que não há diferença entre os pesos médios da percepção de homens e mulheres. 0 mesmo o ocorreu para a liderança transacional $(\mathrm{t}(104)=-1,419 ; \mathrm{p}>0,005)$. Ou seja, homens e mulheres não percebem de forma diferente os comportamentos de liderança identificados em suas líderes.

\section{CONSIDERAÇÕES FINAIS, LIMITAÇÕES E RECOMENDAÇÕES}

O objetivo principal desta pesquisa foi verificar a contribuição de líderes mulheres no nível de comprometimento organizacional, bem como identificar qual é o estilo predominante na liderança feminina a partir da percepção dos liderados. 
Os resultados deste estudo evidenciaram que a liderança transformacional é significativamente relacionada com as dimensões afetiva e normativa do comprometimento organizacional. Como a relação é positiva, é possível inferir que os liderados que percebem em sua líder um perfil transformacional, apresentam um maior grau de comprometimento nestas duas dimensões.

Ressalta-se que não foram encontradas evidências que relacionam os estilos de liderança ao comprometimento em sua dimensão calculativa. Este resultado é sustentado pelo fato que no comprometimento calculativo, o estado psicológico envolvido é a necessidade, baseada nos custos que o indivíduo associa a um benefício econômico.

A pesquisa também revelou que o estilo de liderança mais presente na liderança feminina é o transformacional, com maior média no constructo motivação inspiradora. Nessa perspectiva, o líder age num modelo de comportamento pautado pelo valor da lealdade, buscando o desenvolvimento do colaborador e preocupando-se com o bem-estar individual e coletivo. Os dados revelaram que não há diferença significativa entre homens e mulheres (liderados), quanto à forma de perceber os estilos de liderança transformacional e transacional presentes em suas líderes mulheres.

Embora alguns estudos argumentem que determinados papéis de líderes exigem certos tipos de liderança comuns, independente do gênero (KANTER, 1977; NIEVA; GUTEK, 1981; VAN ENGEN; VANDER LEEDEN; WILLEMSEN, 2001), outras pesquisas respaldadas no comportamento da cidadania organizacional, defendem que comportamentos vão além dos requisitos dos papéis organizacionais (BORMAN, 2004; PODSAKOFF et al., 2000).

Nesse sentido, o interesse substantivo desta pesquisa sugere que a atenção dos pesquisadores para a liderança transformacional, reflete uma mudança cultural que ocorreu nas expectativas sobre os estilos de liderança, que outrora era respaldado no modelo de liderança do "grande homem", nos termos definidos por Eagly (2007). Nessa perspectiva, a boa liderança é cada vez mais definida em termos das qualidades de um bom treinador ou professor, em vez de uma pessoa com características determinista e autocrática, que parece estar congruente com os resultados encontrados neste estudo. Além disso, pesquisas baseadas no questionamento sobre a efetividade da liderança (JUDGE; PICCOLO, 2004, LOWE; KROECK; SIVASUBRAMANIAM, 1996), demonstraram que o estilo de liderança transformacional foi associada a uma maior eficácia.

É importante ressaltar que os aspectos colaborativos e participativos, que aparecem com maior ênfase nos estudos sobre mulheres líderes eficazes, são inerentes a esse estilo culturalmente aprovado de liderança transformacional, na linha de pensamento de Chin (2004). No entanto, a liderança efetiva não é definida apenas pela colaboração, mas especialmente na capacidade de inspirar seus liderados a serem criativos e a ir além dos limites de seus papéis.

Considerando que muitas mulheres têm enfrentado com êxito as barreiras à liderança feminina, e conquistado maior número de posições de liderança do que em qualquer outro período da história (EAGLY, 2007), a reflexão contínua com diferentes recortes teóricos e abordagens metodológicas, são desejáveis. Nesse sentido, recomenda-se novos estudos incluindo abordagens contemporâneas, especialmente sobre o papel da mulher líder no cenário da gestão por competências, indústria 4.0, startups e sucessão familiar, que são as tendências de recursos humanos para os próximos anos.

As principais limitações do estudo dizem respeito à dimensão da amostra, de caráter não probabilístico e por conveniência, portanto, recomenda-se prudência na generalização e interpretação dos resultados encontrados. No presente estudo, não foi realizada a análise 
fatorial devido ao não preenchimento de todos os requisitos para a sua aplicação, pois a amostra ( $\mathrm{N}=106)$ não possui o número de indivíduos para cada item da escala. Desta forma, futuras investigações devem conter um número maior de sujeitos.

Considerando que a maioria das teorias e pesquisas sobre liderança foca no líder do gênero masculino, propõe-se ampliar os estudos e investigações quanto à busca do desenvolvimento de uma melhor compreensão das dinâmicas entre gênero e liderança, especialmente devido ao crescente número de publicações direcionado a outras formas de lideranças inspiracionais, que não foram contemplados no recorte escolhido por este estudo.

\section{REFERÊNCIAS}

AGOSTINHO, A. M. N. Liderança transformacional/transacional: que impacto no cinismo organizacional? 2014. 118 f. Dissertação (Mestrado em Gestão Estratégica das Relações Públicas) - Escola Superior de Comunicação Social, Lisboa 2014.

ARAÚJO, J. M. C. Influência da liderança transformacional na confiança e comprometimento organizacionais. 2011. 109 f. Dissertação (Mestrado em Gestão das Organizações) Associação de Politécnicos do Note - APNOR, Porto, 2011.

BABBIE, E. R. The practice of social research. Belmont, CA: Thomson Wadsworth, 2007.

BASS, B. M. Leadership and performance beyond expectations. New York: The Free Press, 1985.

BASS, B. M. The two faces of charismatic leadership. Leaders Magazine, v. 12, n.4, p. 44-45, 1989.

BASS, B. M. Transformational leadership: military and civilian impact. Mahwah, NJ: Lawrence Erlbaum, 1998.

BASS, B. M.; AVOLIO, B. J. Multifactor leadership questionnaire: Manual and sample set. Redwood City, CA: Mind Garden, 2004.

BASS, B. M.; BASS, R. The Bass Handbook of Leadership: theory, research, \& managerial applications. New York: Free Press, 2008.

BLACKWELL, S.L.S. Using role theory to examine determinants of transformational and transactional leader behavior. Journal of Leadership \& Organizational Studies, v. 10, n. 3, p. 41-51, 2003.

BOEHM, S. A.; DWERTMANN, D.J. G.; BRUCH, H.; SHAMIR, B. The missing link? Investigating organizational identity strength and transformational leadership climate as mechanisms that connect CEO charisma with firm performance. The Leadership Quarterly, 2014.

BORMAN, W. C. The concept of organizational citizenship. Current Directions in Psychological Science, v. 13, p. 238-241, 2004.

CARNEIRO, P. C. C.; ABELHA, D. M.; CAVAZOTTE, F. S. C. N. Liderança Transformacional e Satisfação no Trabalho: Avaliando a Influência de Fatores Situacionais e Contextuais. In: 
ENCONTRO DE GESTÃO DE PESSOAS E RELAÇÕES DE TRABALHO, 2015, Salvador. Anais do EnGPR, 2015.

CHIN, J. L. Feminist leadership: Feminist visions and diverse voices. Psychology of Women Quarterly, v. 28, p. 1-8, 2004.

CÔRTES, F. G. Liderança transformacional e pop-management: um casamento perfeito. In: ENCONTRO NACIONAL DA ASSOCIAÇÃO NACIONAL DE PROGRAMAS DE PÓS-GRADUAÇÃO EM ADMINISTRAÇÃO, 2016. Anais do Enanpad, 2016.

EAGLY, A. H. Female leadership advantage and disadvantage: resolving the contradictions. Psychology of Women Quarterly, v. 31, p 1-12, 2007.

FERREIRA, G C. Estudo das bases de comprometimento organizacional dos funcionários de uma empresa familiar do Rio Grande do Norte. 2011. 71 f. In Dissertação (Programa de PósGraduação em Administração) - Universidade Potiguar. Natal, 2011.

GAO-URHAHN, X.; BIEMANN, T.; JAROS, S. J. How affective commitment to the organization changes over time: a longitudinal analysis of the reciprocal relationships between affective organizational commitment and income. J. Organizational Behavior, v.7, p. 515-536, 2016.

GODOY, M. T. T.; MENDONÇA, H.; DIAS, P. P. M.; MARTINS, E. L. S.; RASSI, W. S. Liderança transformacional e coaching: implicações de pesquisas empíricas no ambiente organizacional. In: ENCONTRO DE GESTÃO DE PESSOAS E RELAÇÕES DE TRABALHO, 2017, Curitiba. Anais do EnGPR, 2017.

GRIFFIN, R. W., MOORHEAD, G. Comportamento organizacional: gestão de pessoas e organizações. São Paulo: Cengage Learning, 2015.

KANTER, R. M. Men and women of the corporation. New York: Basic Books, 1977.

HAIR JR., J. F. et al. Análise multivariada de dados. Porto Alegre: Bookman, 2009.

HELGESEN, S. Eliminando as fronteiras na era do conhecimento e do trabalho personalizado. In HESSELBEIN, F.; GOLDSMITH, M.; SOMERVILLE, I. (Ed). Liderança para o Século XXI. 1.ed. São Paulo: Editora Futura, 2000. p.59-65

JUDGE, T. A.; PICCOLO, R. F. Transformational and transactional leadership: a meta-analytic test of their relative validity. Journal of Applied Psychology, v. 89, p. 901- 910, 2004.

LEE, A.; WILLIS, S.; TIAN, A. W. Empowering leadership: a meta-analytic examination of incremental contribution, mediation, and moderation. Organizational. Behavior. p. 1-20, 2017.

LOWE, K. B.; KROECK, K. G.; SIVASUBRAMANIAM, N. Effectiveness correlates of transformational and transactional leadership: a meta-analytic review of the MLQ literature. Leadership Quarterly, v. 7, p. 385-425, 1996. 
LUKSYTE, A.; UNSWORTH, K.; AVERY, D. R. Innovative work behavior and sex-based stereotypes: examining sex differences in perceptions and evaluations of innovative work behavior. Organizational Behavior, 2017.

MACIEL, C. O.; REINERT, M. Em busca de uma abordagem não-atomizada para o exame das relações entre liderança transformacional e comprometimento organizacional. In: ENCONTRO DE GESTÃO DE PESSOAS E RELAÇÕES DE TRABALHO, 2009, Curitiba. Anais do EnGPR, 2009.

MARÔCO, J. Análise estatística com utilização do SPSS. 2. ed. Lisboa: Edições Sílabo, 2003.

MEYER, J. P., ALLEN, N. J. Commitment in the workplace: theory, research, and application. Thousand Oaks, CA: Sage, 1997.

MEYER, J. P., ALLEN, N. J. A three-component conceptualization of organizational commitment. Human Resources Management Review, v. 1, n. 1, p. 61-89, 1991.

NAZIR, O.; ISLAM, J. U. Enhancing organizational commitment and employee performance through employee engagement: An empirical check. South Asian Journal of Business Studies, v. 6, n. 1, p.98-114, 2017.

NETO, P. L. de O. C. Estatística. 2 ed. São Paulo: Blücher, 2002.

NIEVA, V. G.; GUTEK, B.A. Women and work: a psychological perspective. New York: Praeger, 1981.

PIZZI, P. A influência dos estilos de lideranças transformacional e transacional no nível de comprometimento de uma cooperativa de crédito do sul do Brasil. 2017. 130 f. Dissertação (Mestrado em Gestão de Cooperativas) - Escola de Negócios da PUCPR, Curitiba, 2017.

PODSAKOFF, P. M.; MACKENZIE, S. B.; PAINE, J. B.; BACHRACH, D. G. Organizational citizenship behaviors: a critical review of the theoretical and empirical literature and suggestions for future research. Journal of Management, v. 26, p. 513-563, 2000.

POST, C. When is female leadership an advantage? Coordination requirements, team cohesion, and team interaction norms. J. Organizational. Behavior, v. 36, p 1153-1175, 2015.

RIJAL, S. Leadership style and Organizational culture in learning organization: a comparative study. International Journal of Management and Information Systems; Fourth Quarter. v. 14, n. 5, 2010.

SANTOS FILHO, G. M.; MOURÃO, L. A relação entre comprometimento organizacional e impacto do treinamento no trabalho. Revista Psicologia: Organizações e Trabalho, v. 11, n. 1, p. 75-89, 2011.

VAN ENGEN, M.L.; VANDER LEEDEN, R.; WILLEMSEN, T. M. Gender, context and leadership styles: A field study. Journal of Occupational and Organizational Psychology, v. 74, p. 581598, 2001. 
WEYMER, A. ; MOREIRA, V. R. O papel da liderança transformacional na reconstrução de significados compartilhados de uma unidade estratégica de negócios da área da saúde. Revista de Gestão em Sistemas de Saúde, v. 6, n. 1, p. 23-31, 2017.

YAHAYA, R.; EBRAHIM, F. Leadership styles and organizational commitment: literature review". Journal of Management Development, v. 35, n. 2, p.190-216, 2016. 